\title{
Acculturation in Context: The Moderating Effects of Immigrant and Native Peer Orientations on the Acculturation Experiences of Immigrants
}

\author{
Peter F. Titzmann ${ }^{1} \cdot$ Philipp Jugert ${ }^{2}$
}

Received: 20 March 2015 / Accepted: 1 June 2015/Published online: 20 June 2015

(C) Springer Science+Business Media New York 2015

\begin{abstract}
Immigrant adolescents have to navigate through a complex social environment consisting of, at least, both a native and a co-ethnic community. This study used a multilevel framework to consider two research questions involving this complexity. The individual-level associations of acculturation orientations and acculturative hassles (language and sociocultural adaptation) was assessed in immigrant youths, and whether this association differs depending on the school-level acculturation orientations held by coethnic peers, and the school-level orientations toward immigrants held by native German peers. We then investigated whether acculturative hassles are associated with the psychosocial functioning (self-efficacy, depressive symptoms) of immigrant adolescents. The sample comprised 650 ethnic German Diaspora migrant adolescents (mean age 15.6 years, $53.7 \%$ female) and their 787 native German peers (mean age 15.05 years, $51 \%$ female). The results showed that contextual factors (co-ethnic acculturation orientation, native friendship preferences) moderated the association between the acculturation orientations of adolescent immigrants and both types of acculturative hassles. Acculturative hassles, in turn, were associated with the psychosocial functioning of adolescents. This research demonstrates that a person-by-context perspective is needed to better understand the adaptation of adolescent immigrants. This perspective has to take into account both the native and the co-ethnic peer environment.
\end{abstract}

Peter F. Titzmann

titzmann@jacobscenter.uzh.ch

1 Jacobs Center for Productive Youth Development, University of Zurich, Andreassstr. 15, 8050 Zurich, Switzerland

2 Department of Psychology, University of Leipzig, Leipzig, Germany
Keywords Acculturative stress - Psychological adaptation · Person-by-context perspective $\cdot$ Acculturation . School context

\section{Introduction}

Today's societies accommodate individuals from various ethnic and cultural groups. In Germany, for example, some $19 \%$ of the total population has a background of migration and among adolescents this share is as high as $27 \%$ (Statistisches Bundesamt 2010). These numbers demonstrate the changing ethnic and cultural composition of modern societies, but they also show the particular need to successfully integrate adolescents with a migration background into their new social world. Recent theoretical approaches to the adaptation of immigrant youth emphasize the interaction between individual immigrant adolescents and their context, which is assumed to be key for understanding adolescent adaptation outcomes (Berry 1997; Motti-Stefanidi et al. 2012). It is only recently that research has started to address the complexity of person-by-context interaction, as powerful research methods have become available, such as multilevel hierarchical modeling and large data sets. This study has two aims in addressing this line of research. First, it aims to demonstrate how the individual characteristics of adolescent immigrants are associated with their experiences in their new context, and whether this association differs depending on the peer environment in which these adolescents are embedded. This peer environment consists (among other elements) of two groups: native peers and co-ethnic peers. Both groups are considered simultaneously in this study. The second aim was to demonstrate that acculturative experiences are related to the psychological adaptation of adolescent immigrants. 
A consistent finding from past research is that the aims and expectations of immigrants concerning participation in their host or heritage culture are related to their long-term psychological adaptation to a new cultural setting. Such aims and expectations are reflected in answers to questions such as "Is it considered to be of value to maintain relationships with larger society?" (out-group orientation) and "Is it considered to be of value to maintain one's identity and characteristics?" (in-group orientation) (Berry 1997, p.10). These two questions form the basis for acculturation orientations. Although the concept of acculturation orientation is not without criticism (e.g., Rudmin 2003), it has been found to guide the intentions and behaviors of immigrants and is related to, for example, friendship formation in adolescent immigrants (Titzmann 2014), immigrants' school outcomes (Motti-Stefanidi et al. 2008), and their fit with the cultural values of the majority population (Schiefer et al. 2012). Whether in-group and out-group orientation should be combined in assessment or whether both orientations should be assessed separately, is still under debate (Unger et al. 2007). Recent approaches suggest assessing both of these dimensions separately-with one indicator for individual in-group and another for their out-group acculturation orientation (Rudmin 2003; Ryder et al. 2000). Our study follows this line of research.

Research into acculturation orientations, however, has primarily studied associations at the individual level (between the acculturation orientations of adolescent immigrants and the various outcomes), although established acculturation theories recognize the importance of the context for the adaptation of immigrants to a new culture. Empirical research addressing person-by-context interaction is certainly required, because otherwise responsibility for the success of acculturation processes may be erroneously placed on the immigrants, whereas in reality it is a joint effort between minorities and the majority. Two contextual characteristics can be assumed to be crucial: the attitudes of the majority towards the adaptation of immigrants (Berry 1997; Bourhis et al. 1997; Piontkowski et al. 2002) and the acculturation attitudes of the immigrants' own ethnic community (Berry 1997; Oppedal 2006). In the school environment, adolescent immigrants are confronted with the attitudes of both groups. Native peers can be seen as a source of the majority attitudes, whereas co-ethnic peers represent, to some extent, the acculturation attitudes and expectations of the co-ethnic community. Whether or not the acculturation orientation of an immigrant is beneficial or detrimental to their psychosocial functioning likely depends on its alignment with, or the discrepancy between, the individual and each group. This expected interaction is strongly emphasized by Berry (2006, p. 732) who concludes that "there is no longer any justification for looking at only one side of the intercultural coin in isolation from the other"-clearly pointing out the interactive nature of acculturative processes.

Naturally, the interplay between immigrants and the majority population has received scientific attention. Zagefka and Brown (2002), and Jasinskaja-Lahti et al. (2003) showed that a misfit between immigrant acculturation orientations and the orientations of the majority population is related to greater difficulty in intergroup relations, and to immigrant stress (for more recent evidence see Ramos et al. 2015). Research into the interaction between immigrants and their own ethnic community is less common, but studies show that immigrants reported elevated levels of in-group stress when they were not in accord with the acculturation orientation of their ethnic community (Safdar and Lay 2003; Kunst and Sam 2013). This research shows that both the majority and the immigrant community must be considered when studying the adaptation of adolescent immigrants in context.

These studies contribute substantially to understanding acculturation, and emphasize the need to study the personby-context interaction. To our knowledge, however, none of these studies has simultaneously examined the interplay of individual acculturation orientations with the orientations reported by the co-ethnic and native peers of immigrants. There have also been limitations to previous research. One limitation is that many studies assessed the majority or minority perspective through the perceptions of immigrants (e.g., Zagefka and Brown 2002; Kunst and Sam 2013), which may be biased towards immigrant experiences and may spuriously increase the associations found in adaptation outcomes. Further, even if the attitudes or values of the receiving society were considered (Schiefer et al. 2012; Jasinskaja-Lahti et al. 2003), regional variations (e.g., across different schools) were not taken into account, although the direct environment can be assumed to be more relevant to immigrant adaptation than averages drawn from a heterogeneous receiving society. Our study aimed to overcome some of these limitations. We investigated the acculturation experience of adolescent immigrants as an outcome using a multi-level perspective that can account for individual acculturation orientation (level 1), the specific context marked by the average acculturation orientation of their co-ethnic peers and the average attitude of their native peers at school (level 2), and the person-bycontext interaction.

Our research was embedded in the theoretical framework of Berry (1997). Berry (1997, p. 18) assumed that the success of acculturation is rooted in the acculturation experience of immigrants, which is defined as the "demands (that) stem from the experience of having to deal with two cultures in contact, and having to participate to various extents in both of them." This acculturation experience is the core of Berry's (1997) acculturation 
theory and can be assessed through daily hassles related to the immigrant status of the adolescents (Titzmann et al. 2011). In principle, the theory assumes that the long-term adaptation and psychosocial functioning of immigrants is the result of individuals' dealing with acculturation-related hassles. However, the theory also presents a large number of individual and group-level factors that affect, mediate, or moderate immigrant adaptation processes (including the attitudes of the majority and the co-ethnic community). Berry's theory cannot, therefore, be tested as a whole. Instead it represents a heuristic framework that demonstrates the complexity of acculturative processes and allows predictions to be made for select associations.

Based on this rationale, acculturative hassles can be assumed to play a vital role in the adaptation of immigrants. Our first aim was thus to study whether individuallevel adaptation (including acculturation orientations), the school-context of the adolescents (group-level attitudes of co-ethnic and native school mates), and their interaction, are associated with interindividual differences in these acculturative hassles. Acculturative hassles were differentiated as language hassles and sociocultural adaptation hassles. Language hassles are negative experiences resulting from an insufficient command of the local language and are associated with challenges in communication with peers and teachers (Titzmann et al. 2011). Sociocultural adaptation hassles refer to the behavioral insecurity of adolescent immigrants, or whether the way they behave in a certain situation is appropriate in the new context (Stoessel et al. 2014).

The second research question focused on the association of acculturative hassles and the psychosocial functioning of immigrant adolescents. This association is also proposed in Berry's theory, but might be better explained through theoretical approaches focusing on the adolescent years. Theories of adolescent functioning assume that stressors, which occur in addition to the general challenges of growing up (the biological, psychological, and social changes during the adolescent years), may overburden the coping abilities of these youth. The result is that adolescents cannot deal effectively with the various demands and may be more likely to develop higher levels of psychological maladjustment. Two theoretical approaches in line with these arguments are the model of the development of mental health in adolescence (Petersen et al. 1991) and the general strain theory (Agnew 2003). Neither of these theories were developed for immigrants, but there are some empirical results supporting the assumptions among immigrants (Vinokurov et al. 2002; Titzmann et al. 2014). In this study, we considered two indicators of psychosocial functioning: depressive symptoms and self-efficacy.

\section{The Present Study}

This study focused on a particular group of immigrants, ethnic German Diaspora immigrants (so-called Aussiedler), from the former Soviet Union. Aussiedler are one of the largest immigrant groups in Germany, comprising more than 2.5 million individuals since the 1990s, and are well represented in schools. Aussiedler are the descendants of German settlers who moved to Russia in the eighteenth century. They lived in the territory of the former Soviet Union for many generations and were well adapted to Russian mainstream culture (Dietz 2003). The result of this is that ethnic German adolescents speak little German when they arrive in Germany (Stoessel et al. 2014) and that this group is viewed as not quite German by the German majority and are often labeled "Russians," which reflects a low social status and the negative prejudice held by the German majority population. For this reason, Aussiedler have been found to experience very similar challenges to those of adolescents from other immigrant groups, such as discrimination or language problems. Nevertheless, ethnic German immigrants share a German ancestry, often maintain a mental attachment to Germany, and receive preferential treatment, such as financial support and immediate German citizenship upon arrival. These circumstances make the group of Aussiedler immigrants somewhat unique, because they can blend into the receiving society more easily than other immigrant groups.

\section{Individual-Level Hypotheses}

Given the considerations mentioned earlier, various hypotheses can be derived for the association of in-group and out-group orientation, with both types of acculturative hassles. We expect that individuals with a strong in-group orientation report more acculturative hassles (Hypothesis 1a), because turning to their own ethnic group will decelerate the process of learning new sociocultural knowledge (language, norms of conduct) and will increase the likelihood of language and sociocultural adaptation hassles in everyday life. In a similar vein, we assume an out-group orientation to be associated with fewer acculturative hassles (Hypothesis $1 \mathrm{~b}$ ), because a strong out-group orientation increases the potential to acquire sociocultural knowledge about Germany more quickly so that adolescents can deal with members of the receiving society more competently.

\section{School-Level Hypotheses}

The school context is determined by the average acculturation orientation of an adolescent immigrant's co-ethnic 
peers, the general negative attitudes of natives to immigrants, and native tendencies to form friendships primarily with other native peers (hereafter called friendship homophily). These variables are crucial constructs, creating a particular social school climate that may exert unique effects on the reported acculturative hassles of adolescent immigrants (Brenick et al. 2012). We expected high levels of friendship homophily among native peers (Hypothesis 2a) and high levels of negative prejudice about immigrants in natives (Hypothesis 2b) to be associated with higher levels of language and sociocultural adaptation hassles, because this indicates a low intergroup permeability and a somewhat unfriendly environment for adolescent immigrants. Such a climate can impede adaptation and increase the likelihood of acculturative hassles. We also expected the average acculturation orientation of coethnic peers to be related to the acculturative hassles reported by adolescent immigrants. More specifically, we expected a strong in-group orientation among co-ethnic peers to be related to higher levels of acculturative hassles (Hypothesis 2c), because such an in-group orientation reduces the likelihood of an adolescent receiving help and information about their new society from their in-group. Similarly, in schools where co-ethnic peers endorse an out-group orientation, lower levels of acculturative hassles were expected (Hypothesis 2d), because this climate would allow adolescent immigrants to obtain information about the receiving culture from their out-group-minded co-ethnic peers.

\section{Cross-Level Interaction Hypotheses}

The hypotheses mentioned above refer to the main effects of both individual and context on the level of acculturative hassles. The basic idea of acculturation theories is, however, that adaptation is explained by the interplay between the individual and the context (Berry 1997; Motti-Stefanidi et al. 2012). Misfits between orientations held by the individual and their in-group are, for example, likely to be problematic because orientations held by the in-group represent what is normative for each group member (Thijs and Verkuyten 2014). In line with these considerations, we expected the negative association between the out-group orientation and acculturative hassles of adolescents to be more pronounced in schools where their co-ethnic immigrant peers are also high in out-group orientation (Hypothesis 3a). This expectation is based on the assumption that the effects of immigrant adolescent out-group orientation are boosted if this orientation is supported by their co-ethnic peers. It is expected that these synergetic effects are based on additional information and mutual support that helps in reducing the level of acculturative hassle. We also assumed a positive association between adolescent immigrant in-group orientation and acculturative hassles to be more pronounced in schools where co-ethnic peers also report a strong in-group orientation (Hypothesis $3 b$ ). In this situation, the accordance of individual and co-ethnic ingroup orientation may not only reduce an adolescent's access to socio-cultural knowledge (language, appropriate behavior), but may also exacerbate intergroup tensions through elevated levels of group salience and intergroup boundaries.

The association between individual acculturation orientations and acculturative hassles may also depend on the intergroup climate, particularly on the attitudes and behaviors of native peers. Thijs et al. (2014), for instance, showed that pre-adolescents were more likely to be victimized by other-ethnic peers in classrooms where those peers evaluated their in-group more positively than their out-group. In this study, we expected two variables reflecting the intergroup school climate to affect the association between the acculturation orientations of immigrants and acculturative hassles: the negative view held by native German peers about immigrants and the level of friendship homophily among the native peers. More specifically, we expected the negative association between out-group orientation and acculturative hassles to be less pronounced in schools where native attitudes about the out-group are negative and where their level of friendship homophily is high (Hypotheses $4 a$ for prejudice and $4 \mathrm{~b}$ for homophily). It is expected that such a school climate will involve more intergroup tension, which may increase the socio-cultural insecurity of adolescent immigrants so that an out-group orientation does not necessarily affect the level of experienced hassles. In other words, adolescent out-group orientation does not matter in a context with intergroup tensions, where acculturative hassles are the norm. In a less negative school climate (low negative attitudes and homophily of native peers), however, the negative association of outgroup orientation and acculturative hassles may be particularly strong because immigrants striving for out-group contacts and knowledge are backed by the majority, which should result in more contact and lower levels of acculturative hassles.

Similarly, the positive association between in-group orientation and acculturative hassles was expected to be more pronounced in schools with a climate marked by highly negative prejudice and homophily (Hypotheses $4 \mathrm{c}$ for prejudice and $4 \mathrm{~d}$ for homophily), because this tense intergroup atmosphere may exacerbate the effects of ingroup orientation on acculturative hassles. In a more positive context (low native negative prejudice and homophily), however, the association is expected to be less 
pronounced, because immigrants may receive support and information independent of whether or not they endorse an in-group orientation.

\section{Acculturative Hassles and Psychosocial Functioning}

Following the model of the development of mental health in adolescence (Petersen et al. 1991) described earlier, we assumed that sociocultural adaptation hassles and language hassles would be associated with outcomes related to adolescents' psychosocial functioning. Specifically, we expected sociocultural adaptation hassles to be particularly associated with higher levels of depressive symptoms. Such hassles undermine the major developmental task of developing more mature relations with peers (Havighurst 1972), which is particularly important for adolescent wellbeing. In fact, peer-approval is often more important to the well-being of adolescents than approval by family and community members (Brenick and Killen 2014). Language hassles, conversely, undermine the ability to perform everyday tasks of interaction with the receiving society, from shopping to school-related activities. These hassles can be expected to primarily undermine the adolescent's belief in their ability to complete such tasks and should, thus, predict lower levels of self-efficacy. In short, we expected sociocultural adaptation hassles to be primarily associated with depressive symptoms (Hypothesis 5a); whereas we expected language hassles to be particularly strongly associated with lower levels of self-efficacy (Hypothesis $5 b)$.

\section{Control Variables}

We controlled for a number of background variables in our study: age, gender, the financial situation of the family, parental education, and length of residence. We controlled for age and length of residence because both of these variables are independently associated with adaptation to a new context (Titzmann and Silbereisen 2012) and because prolonged exposure to the host context reduces acculturative stress (Miranda and Matheny 2000). Gender was included, because male and female adolescents may differ in dealing with stress, which is seen as a major reason for sex differences in psychological adaptation (Petersen et al. 1991). The financial situation of the family and parental education were included as indicators of the socio-economic status of a family. Financial and educational resources are known to affect many developmental outcomes across childhood and adolescence (Bradley and Corwyn 2002) and also the degree to which acculturative stress is experienced (Williams and Berry 1991).

\section{Method}

\section{Participants and Procedure}

The sample for the present analyses was drawn from a large multidisciplinary research project on the adaptation of Diaspora immigrant adolescents from the former Soviet Union. Adolescent Aussiedler and their native peers (age range from 11 to 19 years) were approached through schools and only participated if neither adolescents nor their parents objected to participation. The questionnaires were completed at school and so we not only collected data from the adolescents themselves, but also received information from their co-ethnic and native peers, which served as measure for the general school environment. Participants came from 27 schools in nine cities in four federal states (North Rhine Westphalia, Hesse, Thuringia, Saxony). Cities with 100,000-200,000 citizens were selected, because these host a substantial number of Aussiedler, which ensured that Aussiedler attended all schools participating in the project. The students self-identified as Aussiedler or native. Sampling was conducted in cooperation with a reputed field research organization (ZUMA, Mannheim, Germany) and the sampling procedure ensured that adolescents in school grades 5 through 12 from all school academic and vocational streams were representatively included. Schools asked to be involved in the data collection, in order to ensure minimal interference with daily school routines. As a result, the native peers in our sample could not be drawn randomly from the school population, but were partly selected based on availability and restrictions in their curriculum. Specifically, native adolescent participants were selected based on age, class, and school type in order to ensure a native sample that is highly comparable with the Aussiedler sample. Nevertheless, this approach limits the representativeness of this group. On average, about $7 \%$ of students in the selected schools were sampled. Overall, data from 650 Aussiedler adolescents $(M$ age $=15.62, S D=2.16 ; 53.8 \%$ female $)$ from the FSU (all first generation immigrants) and 787 native German adolescents were analyzed $(M$ age $=15.05$, $S D=2.47 ; 51 \%$ female). The average length of stay for Aussiedler adolescents was 7.12 years $(S D=3.84)$ and their average age at migration was 8.74 years $(S D=4.52$, Range 0.01-18.17).

\section{Individual-Level Measures}

\section{Immigrant In-group and Out-group Orientation}

Both in-group and out-group orientation were measured based on a two-dimensional instrument assessing acculturation orientations (Ryder et al. 2000). Out-group orientation 
was assessed via the mean of three items: "I enjoy social activities with native adolescents," "I would be willing to have a girlfriend/boyfriend who is native German," and "I can imagine having native German friends." In-group orientation was assessed via the mean of the same three items. These were rephrased, however, to address contact with ingroup members, for example, "I enjoy social activities with other Aussiedler." Adolescents rated their agreement with each statement on a 6-point Likert scale ranging from "I agree" to "I disagree" (see Table 1 for all scale reliability indices).

\section{Language Hassles and Sociocultural Adaptation Hassles}

Both types of hassles were assessed over the last 12 months and adolescents rated how often they experienced each hassle ranging from 1 "never" to 5 "more than 10 times" on a 5-point scale. Six hassles were related to language and seven to sociocultural adaptation hassles. Sociocultural adaptation hassles were, for example, "I was together with natives and did not know how to behave" or "I realized that I don't belong to Germany" (Stoessel et al. 2014). Language hassles comprised situations such as "I had problems in class/at work because my German was not good enough" or "I felt alienated in Germany, because my language abilities are not sufficient" (Titzmann et al. 2011). The mean of the items for each variable was used in the analyses.

\section{Depressed Mood}

Depressed mood was assessed by the mean of nine items from the Child Behavior Checklist (Achenbach 1991). Adolescent immigrants were asked to rate statements such as "I feel lonely," "I am fearful/anxious," "I am unhappy/ sad/depressed," and "I worry a lot" on a 6-point Likerttype scale ranging from 1 "does not apply" to 6 "does apply."

\section{Self-Efficacy}

Adolescent self-efficacy was measured with four items from a well-known instrument (Schwarzer and Jerusalem 1995). Sample items are "I can always manage to solve difficult problems if I try hard enough" or "I am confident that I could deal efficiently with unexpected events." Adolescents responded using a six-point scale ranging from 1 "does not apply" to 6 "does apply" and the mean was used for our analyses.

\section{Control Variable Measures}

The financial situation of the family was measured with a single item ("In your opinion the financial situation of your family here in Germany, is...." The item was rated on a scale from 1 "very bad" to 5 "very good." Parental education was assessed by asking for the highest educational qualification of each parent on a 6-point index varying between 0 "no formal school qualification" to 5 "more than one university degree." The highest reported educational level of either the father or mother was used in the analyses. The adolescent's age, gender, and length of residence were also noted in the questionnaire.

\section{School-Level Measures}

\section{Negative Attitudes About Aussiedler}

Native Germans rated their agreement to seven items adapted from Förster et al. (1993), based on common prejudices toward minorities, such as "Aussiedler just want to live at the expense of Germans" or "Aussiedler tend to violence and criminality." Items were rated on a scale from 1 "does not apply" to 6 "does apply" $(\alpha=.88)$ and were aggregated across all native German adolescents in each school to assess school-level negative prejudice. We calculated the generalizability coefficient reported by O'Brien (1990) in order to estimate how well the aggregated score reflected the actual school context. The generalizability coefficient indicates the extent to which the same mean value for a school would emerge if another random set of students were selected as respondents. The generalizability coefficient for this measure was .82. This instrument showed its validity for assessing the attitudes towards Aussiedler in earlier research (Titzmann et al. 2015).

\section{Friendship Homophily}

Friendship homophily in native students was defined as the percentage of intra-ethnic friends among all their friends, which is an index that has demonstrated validity in various studies (Titzmann 2014). Participants reported the number of their friends who were (a) native Germans, (b) Aussiedler and (c) other immigrants. Friendship homophily was calculated by dividing the number of intra-ethnic friends by the total number of intra- and interethnic friends multiplied by 100 . Thus, individuals could vary in friendship homophily between 0 and $100 \%$ with higher values indicating friendships that were predominantly within their own ethnic group. The resulting measure was then aggregated for native German participants at the school level (generalizability coefficient $=.86$ ). 
Table 1 Individual-level variables: means, standard deviations, and bivariate correlations

\begin{tabular}{|c|c|c|c|c|c|c|c|c|c|c|c|c|c|}
\hline & M & SD & $\alpha$ & 2 & 3 & 4 & 5 & 6 & 7 & 8 & 9 & 10 & 11 \\
\hline 1 Language hassles & 1.90 & 0.96 & .87 & $.68 * *$ & $.27 * *$ & $-.20 * *$ & $.09 *$ & $.21 * *$ & $-.55^{* *}$ & $-.25^{* *}$ & $.14 * *$ & .03 & $-.25^{* *}$ \\
\hline $\begin{array}{l}2 \text { Sociocultural adaptation } \\
\text { hassles }\end{array}$ & 1.86 & 0.79 & .76 & & $.32 * *$ & $-.13 * *$ & .04 & $.17 * *$ & $-.37 * *$ & $-.22 * *$ & $.16^{* *}$ & .08 & $-.29 * *$ \\
\hline 3 Depressive symptoms & 1.98 & 0.95 & .88 & & & $-.18 * *$ & $.25^{* *}$ & $.15^{* *}$ & -.08 & $-.23 * *$ & .06 & .01 & -.07 \\
\hline 4 Self-efficacy & 4.13 & 1.14 & .81 & & & & -.06 & .03 & $.16^{* *}$ & $.09 *$ & .07 & $.16^{*}$ & $.18^{* *}$ \\
\hline $\begin{array}{l}5 \text { Sex }(0=\text { male } \\
1=\text { female })\end{array}$ & - & - & - & & & & & $.12 * *$ & -.06 & $-.09^{*}$ & -.04 & .07 & -.03 \\
\hline 6 Age & 15.62 & 2.16 & - & & & & & & $-.09 *$ & $-.24 * *$ & $.20 * *$ & $.20 * *$ & $-.15^{* *}$ \\
\hline 7 Length of residence & 7.12 & 3.84 & - & & & & & & & $.21 * *$ & $-.20 * *$ & .06 & $.26^{* *}$ \\
\hline $\begin{array}{l}8 \text { Family's financial } \\
\text { situation }\end{array}$ & 3.62 & 0.78 & - & & & & & & & & -.04 & -.03 & $.08^{*}$ \\
\hline 9 Parental education & 2.40 & 1.40 & - & & & & & & & & & -.03 & -.07 \\
\hline $\begin{array}{l}10 \text { Immigrant in-group } \\
\text { orientation }\end{array}$ & 5.16 & 1.22 & .81 & & & & & & & & & & $.09 *$ \\
\hline $\begin{array}{l}11 \text { Immigrant out-group } \\
\text { orientation }\end{array}$ & 4.00 & 1.53 & .86 & & & & & & & & & & \\
\hline
\end{tabular}

\section{Immigrant In-group Orientation and Immigrant Out-group Orientation}

These co-ethnic acculturation orientations at the group level were assessed with the same items described in the individual-level variable section. To form the school-level aggregate measure, the individual levels of Aussiedler adolescents were aggregated at the school level (generalizability coefficient $\mathrm{in}_{\text {-group orientation }}=.47$, generalizability coefficient $_{\text {out-group orientation }}=.72$ ). Although the somewhat lower generalizability coefficient for in-group orientation is not uncommon in aggregate level data (O'Brien 1990), it does point to less generalizability for this school-level indicator.

\section{School-Level Control Variable}

The share of Aussiedler adolescents per school was taken into account. This variable was provided by school principals according to their enrolment statistics.

\section{Plan for Analysis}

As we were interested in examining interactions between individual variables and school-level variables, we analyzed the data with mixed linear models (MLM) and maximum-likelihood (ML) estimation using HLM 6.08 (Raudenbush et al. 2005). ML estimation was used to compare nested models with respect to model fit. In Level One (individual level), we entered the individual-level variables immigrant in-group and out-group orientation, and our control variables family's financial situation, parental education, gender, age, and length of residence. In Level Two (school level), we included the percentage of Aussiedler adolescents at school, co-ethnic in-group orientation, co-ethnic out-group orientation, negative native attitudes about Aussiedler, and native friendship homophily. We included school ethnic composition as a control variable for different opportunities for intergroup contact. All predictor variables were grand-mean centered to facilitate interpretation of the effects. Before including cross-level interaction effects, we tested whether any of the slopes of our explanatory variables had a significant $(p<.05)$ variance component between the groups by letting slopes vary randomly (c.f., Hox 2002). This was done on a variable-by-variable basis.

\section{Results}

The means, standard deviations, and bivariate correlations of all variables are shown in Table 1 (individual variables), and Table 2 (school-level variables). Prior to hypotheses testing, we analyzed the mean levels of language and sociocultural adaptation hassles by estimating separate intercept-only models without predictors. The intraclass correlation suggested that $18 \%$ of the variance for language hassles and $11 \%$ of the variance for sociocultural adaptation hassles was attributable to schools. Two sets of mixed linear models were conducted, with each type of 
Table 2 School-level variables: range, means, standard deviations, and bivariate correlations

\begin{tabular}{lcrrrrr}
\hline & Range & M & SD & 2 & 3 & 4 \\
\hline 1 School ethnic composition (\% of Aussiedler) & $0.14-38.40$ & 9.09 & 8.11 & .26 & $-.51^{* *}$ & .10 \\
2 Native negative attitudes about Aussiedler & $2.10-4.04$ & 2.98 & 0.50 & -.37 \\
3 Native friendship homophily & $46.65-92.61$ & 73.05 & 12.53 & -.24 & -.08 & .07 \\
4 Immigrant in-group orientation & $3.95-5.83$ & 5.15 & 0.44 & & -.12 \\
5 Immigrant out-group orientation & $3.25-5.06$ & 4.24 & 0.61 & & -.12 \\
\hline
\end{tabular}

Schools $(\mathrm{n}=27)$

$* p<.05 ; * * p<.01$

hassle serving as the dependent variable. In the first model, we included all individual-level and group-level predictors simultaneously (Model 1). The cross-level interaction terms were added in the next model (Model 2) in order to see whether adding these interactions can improve model fit. The results of the final models for both outcomes (Model 2) are summarized in Table 3. Coefficients for Model 1 are not shown as these did not differ substantially from the coefficients in the final model.

\section{Predictors of Interindividual Differences in Acculturative Hassles}

\section{Individual Level Associations}

Hypotheses at the individual level stated that adolescent ingroup orientation (Hypothesis 1a) and out-group orientation (Hypothesis 1b) would be associated with higher versus lower levels of acculturative hassles. The results supported both these hypotheses for language hassles. Associations between adolescent in-group orientation $(b=0.10, p<.05)$ and out-group orientation $(b=-0.07$, $p<.05)$ were significantly associated with language hassles in the expected direction. Two of the control variables were associated with language hassles. Longer residence in the host country $(b=-0.12, p<.001)$ and better family finances $(b=-0.16, p<.01)$ were both and independently associated with fewer language hassles.

The results were very similar for sociocultural adaptation hassles. Again, the level of immigrant adolescent ingroup orientation $(b=0.13, p<.01)$ was associated with more sociocultural adaptation hassles whereas the level of immigrant adolescent out-group orientation $(b=-0.14$, $p<.001$ ) was associated with fewer sociocultural adaptation hassles. These results also supported Hypotheses 1a and $1 \mathrm{~b}$ for sociocultural adaptation hassles. The same two control variables were associated with sociocultural adaptation hassles: length of residence $(b=-0.06, p<.001)$ and the financial situation of the family $(b=-0.14$, $p=.054)$ were, again, both related to lower levels of sociocultural adaptation hassle.

\section{School Level Associations}

At the school level, we expected acculturative hassles to be positively associated with native peer homophily (Hypothesis 2a), negative prejudice in native peers (Hypothesis $2 b$ ), and a strong in-group orientation among co-ethnic peers (Hypothesis 2c). Lower levels of acculturative hassles were expected in schools with a strong out-group orientation of adolescents' co-ethnic peers (Hypothesis 2d). The results in Table 2 show that none of these hypotheses was supported; neither for language hassles nor for sociocultural adaptation hassles.

\section{Cross-Level Interactions}

A major aim of this study was to investigate the interplay between the individual immigrant adolescents and the two ethnic peer groups in their school. Several hypotheses thus focused on cross-level interactions. Two of these hypotheses referred to the interaction of adolescent immigrants with their co-ethnic peers. We expected the negative association between adolescent out-group orientation and acculturative hassles to be more pronounced in schools where their co-ethnic immigrant peers were also high in out-group orientation (Hypothesis 3a) and the positive association between adolescent immigrant in-group orientation and acculturative hassles to be more pronounced in schools where the co-ethnic peers also report a strong ingroup orientation (Hypothesis $3 b$ ). We formulated four hypotheses about the interplay between individual immigrant adolescents and the native peer group. The negative association between out-group orientation and acculturative hassles was expected to be less pronounced in schools where native out-group attitudes were particularly negative (Hypotheses 4a) and where the level of friendship homophily among natives was high (Hypothesis $4 b$ ). We also 
Table 3 Fixed and random effects [95\% confidence intervals] of mixed linear models predicting acculturative language hassles and sociocultural adaptation hassles

\begin{tabular}{|c|c|c|}
\hline & Language Hassles & Sociocultural Adaptation Hassles \\
\hline \multicolumn{3}{|l|}{ Level 1-individual level } \\
\hline Intercept & $1.95 * * *[1.83,2.07]$ & $1.93 * * *[1.83,2.03]$ \\
\hline Sex $(0=$ male, $1=$ female $)$ & $-0.08[-0.24,0.08]$ & $0.02[-0.12,0.16]$ \\
\hline Age & $0.03[-0.01,0.07]$ & $0.02[-0.02,0.06]$ \\
\hline Length of residence & $-0.12 * * *[-0.14,-0.10]$ & $-0.06 * * *[-0.08,-0.04]$ \\
\hline Family's financial situation & $-0.16 * *[-0.26,-0.06]$ & $-0.14[-0.27,0.00]$ \\
\hline Parental education & $0.02[-0.04,0.08]$ & $0.03[-0.01,0.07]$ \\
\hline Immigrant in-group orientation & $0.10^{*}[0.02,0.18]$ & $0.13 * *[0.05,0.21]$ \\
\hline Immigrant out-group orientation & $-0.07 *[-0.13,-0.01]$ & $-0.14 * * *[-0.20,-0.08]$ \\
\hline \multicolumn{3}{|l|}{ Level 2-school level } \\
\hline School ethnic composition & $-0.01[-0.03,0.01]$ & $0.00[-0.01,0.01]$ \\
\hline Native negative attitudes about Aussiedler & $0.03[-0.19,0.25]$ & $0.01[-0.15,0.17]$ \\
\hline Native friendship homophily & $-0.01[-0.03,0.01]$ & $0.00[-0.01,0.00]$ \\
\hline Immigrant in-group orientation & $0.05[-0.24,0.34]$ & $-0.03[-0.27,0.21]$ \\
\hline Immigrant out-group orientation & $-0.02[-0.26,0.22]$ & $0.15[-0.03,0.33]$ \\
\hline \multicolumn{3}{|l|}{ Cross-level interactions } \\
\hline Immigrant in-group orientation $\times$ native negative attitudes about Aussiedler & $0.01[-0.13,0.15]$ & $-0.01[-0.13,0.11]$ \\
\hline Immigrant in-group orientation $\times$ native friendship homophily & $0.01 *[0.00,0.01]$ & $0.01 *[0.00,0.01]$ \\
\hline Immigrant in-group orientation $\times$ immigrant in-group orientation & $0.03[-0.15,0.21]$ & $0.06[-0.10,0.22]$ \\
\hline Immigrant out-group orientation $\times$ native negative attitudes about Aussiedler & $0.02[-0.10,0.14]$ & $-0.02[-0.12,0.08]$ \\
\hline Immigrant out-group orientation $\times$ native friendship homophily & $0.00[0.00,0.00]$ & $0.00[0.00,0.00]$ \\
\hline Immigrant out-group orientation $\times$ immigrant out-group orientation & $-0.09^{\dagger}[-0.21,0.02]$ & $-0.17 * *[-0.27,-0.07]$ \\
\hline \multicolumn{3}{|l|}{ Residual variances } \\
\hline For intercept & $0.02 * *[0.01,0.03]$ & $0.01 * *[0.00,0.02]$ \\
\hline For immigrant out-group orientation & & $0.00[0.00,0.00]$ \\
\hline For family's financial situation & & $0.04 *[0.02,0.06]$ \\
\hline \multicolumn{3}{|l|}{ Fit } \\
\hline Deviance (no. of parameters) & $1171.23(21)$ & $1033.73(26)$ \\
\hline$\chi^{2} \Delta(6)$ & $10.9^{\dagger}$ & $20.03 * *$ \\
\hline
\end{tabular}

$p<.10 ; * p<.05 ; * * p<.01 ; * * * p<.001$

expected the positive association between in-group orientation and acculturative hassles to be more pronounced in schools with a climate marked by high negative prejudice (Hypotheses 4c) and high levels of homophily (Hypotheses 4d).

For language hassles, the deviance test showed that the change in model fit between Model 1 and Model 2 was marginally significant, $\chi^{2} \Delta(6)=10.9, p=.092$. Two significant cross-level interactions emerged in Model 2 and thus added information by qualifying the main effects of Model 1. The first involved the association between immigrant in-group orientation and language hassles, which was moderated by the friendship homophily of native German peers $(b=.01, p<.05)$. This moderation effect is depicted in Fig. 1a. The three lines in the figures represent the regression lines for the 25th, 50th and 75th percentile of the school-level moderator. As can be seen from Fig. 1a, the associations between immigrant ingroup orientation and language hassles varied depending on the extent of friendship homophily among native German peers at the school level: individual in-group orientation was only associated with more language hassles in schools with medium to high levels of German peer homophily, whereas almost no effect was found in schools with low levels of homophily. The second cross-level interaction (see Fig. 1b) indicated that out-group orientation was associated with fewer language hassles, but this effect was only found in schools where fellow Aussiedler were on average also medium to high in out-group orientation $(b=-0.09, p<.10)$. Although this effect is only a trend $(p<.10)$, we report this interaction here, because it reached significance $(b=-0.09, p<.05)$ when all other 

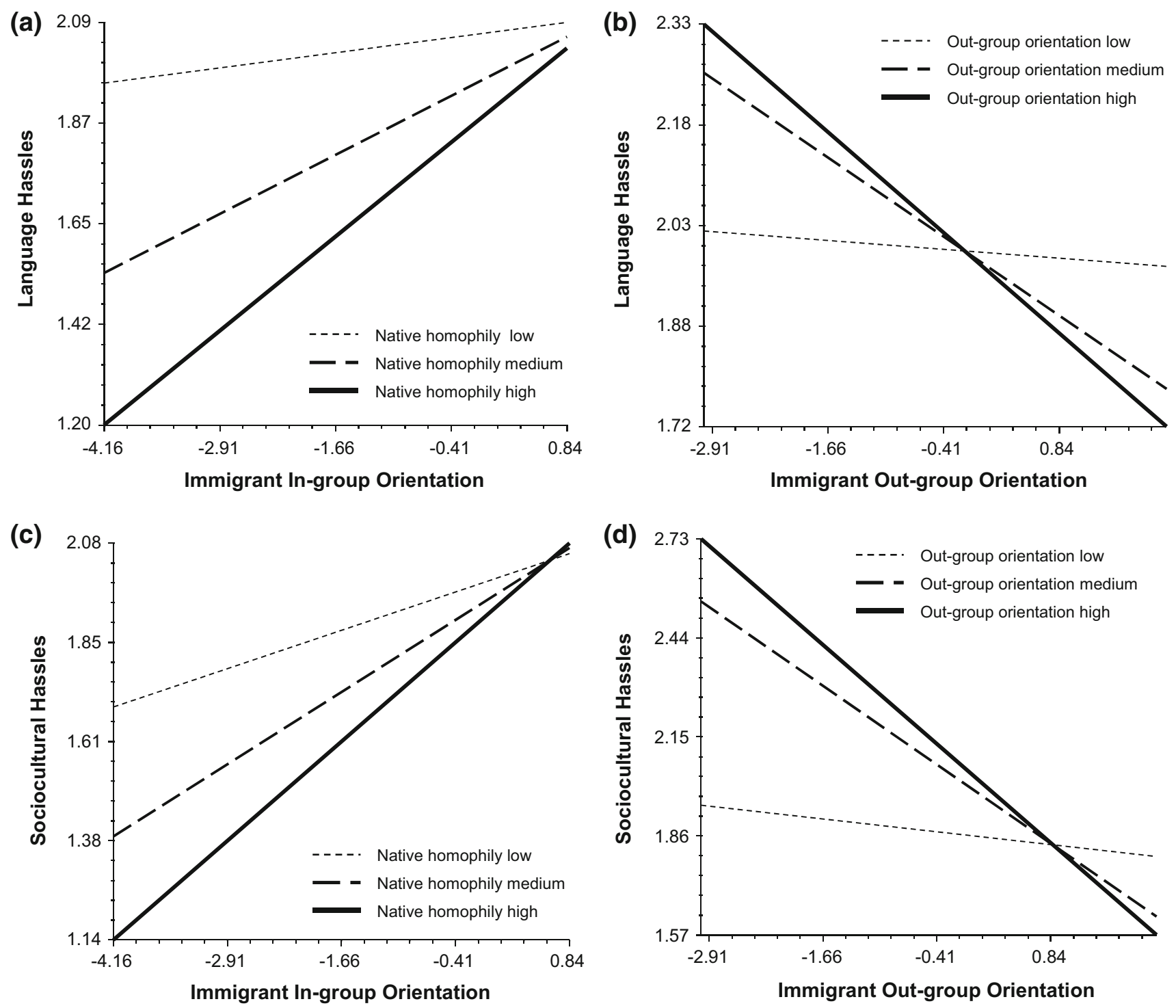

Fig. 1 Cross-level interactions between individual acculturation orientation and the group context: $\mathbf{a}$ in-group orientation and language hassles by school-level native peer friendship homophily; $\mathbf{b}$ out-group orientation and language hassles by school-level co-ethnic out-group

non-significant interactions were excluded from the analysis.

The deviance test showed that the change in model fit between Model 1 and Model 2 was significant for sociocultural adaptation hassles, $\chi^{2} \Delta(6)=20.03, p<.01$ indicating that the cross-level interactions added significantly to the prediction of sociocultural adaptation hassles. Again, two cross-level interaction effects qualified the main effects of immigrant in-group and out-group orientation. The first involved the association between immigrant in-group orientation and sociocultural adaptation hassles, which was moderated by the friendship homophily of native German peers $(b=.01, p<.05)$. This

orientation; c in-group orientation and sociocultural adaptation hassles by school-level native peer friendship homophily; d outgroup orientation and sociocultural adaptation hassles by school-level co-ethnic out-group orientation

moderation effect is depicted in Fig. 1c. As can be seen, the positive association between immigrant in-group orientation and sociocultural adaptation hassles varied depending on the school-level friendship homophily of native German peers and was particularly strong in schools with medium to high levels of German peer homophily. In schools with low levels of native homophily, the association was less pronounced, albeit significant. The second cross-level interaction $(b=-0.17, p<.01)$ indicated that out-group orientation was associated with having fewer sociocultural adaptation hassles in schools where fellow Aussiedler were on average medium to high in out-group orientation (see Fig. 1d). In schools where Aussiedler peers 
reported a low level of out-group orientation on average, the negative association was significantly less pronounced. Taken together, the cross-level interactions supported Hypotheses $3 \mathrm{a}$ and Hypothesis $4 \mathrm{~d}$ for both types of acculturative hassles (language and sociocultural adaptation hassles). All other hypotheses involving cross-level interactions had to be rejected.

\section{Associations Between Acculturative Hassles and Psychological Adaptation}

Our last research question focused on the association between acculturative hassles and two indicators for the psychosocial functioning of adolescents: depressive symptoms and self-efficacy. We expected sociocultural adaptation hassles to be primarily associated with depressive symptoms (Hypothesis 5a) and language hassles to be predominantly associated with lower levels of self-efficacy (Hypothesis 5b). We ran another set of mixed linear models with depressive symptoms and self-efficacy as the outcome variables in order to test whether language hassles and sociocultural adaptation hassles indeed predict the psychosocial functioning of immigrant adolescents. Gender, age, length of residence, financial situation, parental education, and school ethnic composition were entered as covariates. The results for these analyses are presented in Table 4. For depressive symptoms, sociocultural adaptation hassles $(b=0.34, p<.001)$ were associated with more depressive symptoms, while language hassles ( $b=0.09, p=.136)$ were not. For self-efficacy, sociocultural adaptation hassles $(b=0.01, p=.933)$ were not significantly associated with this outcome, whereas language hassles were associated with having less self-efficacy $(b=-0.19, p<.05)$. These results supported our
Hypotheses 5a and 5b. Several control variables were also associated with the indicators of psychosocial functioning. Females reported slightly higher levels of depressive symptoms $(b=0.50, p<.001)$ and lower levels of selfefficacy $(b=-0.22, p<.05)$ than males. Length of residence was positively associated with depressive symptoms $(b=0.03, p<.05)$, such that immigrant adolescents showed slightly elevated levels of depressive symptoms the longer they had been in Germany. The family's financial situation was negatively associated with depressive symptoms $(b=-0.17, p<.01)$ and positively with self-efficacy $(b=0.14, p<.05)$. Immigrant adolescents whose families were financially better off reported lower levels of depressive symptoms and higher self-efficacy than their less affluent peers.

\section{Discussion}

Immigrant adolescents do not develop in a social vacuum and their behavior and psychological functioning have long been assumed to be the result of interaction with their social environment. The major aim of this study was to contribute to this debate by taking a person-by-context interaction perspective to examine how the contextual features of the school (acculturation orientations held by co-ethnic peers and native's orientation toward Aussiedler and homophily) moderate the association between the acculturation orientations of adolescent immigrants and their acculturation experience assessed through acculturative hassles. The second aim of this research was to show that acculturative hassles in the domain of language and sociocultural adaptation are associated with the psychosocial functioning of immigrant adolescents. The major
Table 4 Fixed and random effects [95\% confidence intervals] of mixed linear models predicting depressive symptoms and self-efficacy

\begin{tabular}{lcc}
\hline & Depressive symptoms & Self-efficacy \\
\hline Level 1-Individual level & $2.01 * * *[1.92,2.09]$ & $4.21 * * *[4.07,4.34]$ \\
Intercept & $0.50 * * *[0.32,0.67]$ & $-0.22 *[-0.42,-0.02]$ \\
Sex $(0=$ male, $1=$ female $)$ & $0.02[-0.02,0.06]$ & $0.01[-0.04,0.06]$ \\
Age & $0.03 *[0.00,0.05]$ & $0.02[-0.01,0.06]$ \\
Length of residence & $-0.17 * *[-0.28,-0.06]$ & $0.14 *[0.01,0.27]$ \\
Family's financial situation & $0.02[-0.04,0.08]$ & $0.09 *[0.02,0.16]$ \\
Parental education & $0.34 * *[0.20,0.47]$ & $0.01[-0.15,0.17]$ \\
Sociocultural adaptation hassles & $0.09[-0.03,0.21]$ & $-0.19 * *[-0.33,-0.05]$ \\
Language hassles & $0.00[0.00,0.01]$ & $0.04 *[0.02,0.06]$ \\
Residual variances & & $1417.91(10)$ \\
For intercept & $1288.80(10)$ & \\
Fit & & \\
Deviance (no. of parameters) & & \\
\hline$* p<.05 ; * *<.01 ; * * p<.001$ & &
\end{tabular}


finding of our study was that acculturative hassles are indeed associated with the interaction of individual immigrant acculturation orientations and the particular context in which an adolescent is situated. This context is simultaneously shaped by native and co-ethnic (Aussiedler) peers. More specifically, the findings indicate that immigrant individual out-group orientation was only associated with fewer hassles when their co-ethnic Aussiedler peers at school reported a medium to high out-group orientation. When their co-ethnic peer out-group orientation was low, no association between individual immigrant out-group orientation and acculturative hassles was found. The behavior of the native majority adolescents also mattered. Immigrant in-group orientation was more strongly associated with more hassles when native friendship homophily was high, which may be a sign of restricted group permeability.

\section{Predictors of Acculturative Hassles}

Although the interactions of individuals and context were certainly the most interesting findings, we also found unique effects at the individual level. The individual ingroup orientation of immigrants was associated with more, and their out-group orientation with fewer acculturative hassles. These findings show that an out-group orientation can help in the adaptation of Aussiedler in Germany, a result that is in line with research on Turkish-origin youth in Germany. According to a recent review, a high outgroup orientation was most predictive of the successful adaptation of Turkish-origin youth in Germany (Frankenberg et al. 2013). This implies that the positive attitudes of immigrants toward the majority help in dealing with the demands of acculturation and should be promoted -at least in the German context studied here. In-group orientation was associated with more hassle on the individual level, which may lead to the conclusion that in-group orientation should be reduced, for example through intervention programs. We strongly caution against this conclusion, however, because our study focused solely on out-group hassles (language and sociocultural adaptation). For in-group hassles (e.g., conflicts with parents and the co-ethnic community) a low in-group orientation may be a risk leading to family distancing and alienation (Hwang 2006), a loss of in-group support (Bochner et al. 1977), and impaired ethnic identity development. For this reason, the effects of in-group orientation need more research, including additional outcomes, before conclusions can be drawn.

It was somewhat surprising that we found no significant main effects at the school level. One reason for this may be that the variability across schools was somewhat limited and that more schools would have revealed the expected results. As other studies with a similar number of schools did reveal school-level effects on immigrant experiences of discrimination (Brenick et al. 2012), the number of schools may not be the sole issue. Instead, the missing effects may be related to the nature of our outcomes. Language and sociocultural adaptation hassles reflect both the linguistic and social competences of adolescent immigrants and the intergroup situation, whereas discrimination is a more direct assessment of the intergroup situation. Future research with more schools may reveal whether the schoollevel effects are smaller for some outcomes (e.g., for the hassles assessed in this study) and require larger samples of schools, or whether specific outcomes can only be explained by person-by-school interactions.

Although not all of our hypotheses regarding cross-level interactions were confirmed, the cross-level interactions that were found allow two general conclusions to be drawn. The first is that the understanding of the adaptation of adolescent immigrants has to go beyond the perspective of immigrant relations with native peers. The co-ethnic community also needs to be taken into account: in our data, adolescent out-group orientation was only associated with acculturative hassles if the co-ethnic peers had a strong out-group orientation. The second general conclusion is that cross-group behaviors have the greatest potential to affect acculturative experience in terms of hassles: When focusing on contextual variation in terms of native German homophily (immigrant adolescents' outgroup), it was the in-group orientation that mattered. When focusing on the contextual variation in terms of co-ethnic peers (immigrant adolescents' in-group), the out-group orientation toward natives revealed significant interaction effects. Further research is needed to test whether these two general conclusions are limited to this study or can also be identified in other samples and contexts. Research should also turn to the mechanisms involved. We assumed that the provision of support and information is a crucial element in explaining why some adolescents experience more or less hassle, but this assumption has to be tested. If it is verified, interventions may deliver easily applicable measures (information and support campaigns). In addition to these conclusions, it is noteworthy that the analyses revealed similar results for language and sociocultural adaptation hassles. This similarity was to be expected given the fact that both scales assess hassles related to the adaptation to majority culture, but it also serves as a validation of findings. Despite this similarity we acknowledge, however, that the cross-level interactions for language hassles were more modest than those for sociocultural adaptation hassles and require more, particularly longitudinal, research to uncover more about their practical meaning for the long-term development of adolescent immigrants. 


\section{Acculturative Hassles and Psychosocial Functioning}

Our study also showed the association between acculturative hassles and psychosocial functioning in terms of selfefficacy and depressive symptoms. This result is in line with earlier findings on correlates of acculturative hassles (e.g., Vinokurov et al. 2002; Lay and Safdar 2003) and corroborates the assumed relevance of acculturative hassles in acculturation processes. What is new, though, is the finding that acculturative hassles explain specific outcomes, with sociocultural adaptation hassles being associated with depressive symptoms and language hassles being related to self-efficacy. Perhaps, the different associations should not be overemphasized, but they do demonstrate that research might profit from paying more attention to the diversity of adolescent experiences. Future research should, therefore, expand the assessment of acculturative hassles. Other out-group hassles, such as discrimination hassles, may play a different and unique role in the adaptation process of adolescents. More attention should also be paid to the role of in-group hassles, which may have very different consequences for adolescent adaptation and wellbeing than out-group hassles. In-group hassles are feelings of being isolated in the ethnic community, or family hassles related to the different pace of adaption in parents and their children (Lay and Safdar 2003). The interplay of these different types of hassles with adolescent coping processes and their endowment with resources and support may add an important component to the understanding of the effects of adolescent immigrant experiences.

\section{Strengths and Limitations}

Our study has various strengths. These include the multilevel approach with the direct assessment of immigrant adolescents as well as their native and co-ethnic peers in a single comprehensive analytical framework. This framework adds to previous research by examining associations of constructs at the individual level of immigrant adolescents in relation to the attitudes and behaviors of their ethnic community and the orientation of their native adolescent peers. Such interactive models certainly help to increase knowledge about acculturation processes of immigrant adolescents.

Nevertheless, limitations of our research must also be mentioned. First, our research focused on a somewhat privileged group of ethnic German Diaspora immigrants (Aussiedler) with cultural roots in Germany. These immigrant adolescents face a very different situation to other immigrant groups, such as Turkish adolescents, and they certainly have more potential for blending into mainstream society. We assume, however, similar individual-by-context associations for other ethnic groups. The effects may even be stronger for Turkish adolescents, the second largest immigrant group in Germany, as research suggests that Turkish youth are more strongly affected by peer norms than other ethnic groups (Jugert et al. 2013), and because the attitudes of German natives toward Turkish immigrants are assumed to be particularly negative (Frankenberg et al. 2013). Only comparative research can address such issues of generalizability, but is still rare. Nonetheless, our research adds to the growing body of research on the phenomenon of Diaspora migration, of which Aussiedler are only one prominent group. Tsuda (2009) demonstrated that a large and growing number of countries are confronted with this type of immigration and these countries are in need of empirical results on this specific type of immigrants.

Another limitation of this study is the focus on two way interactions between the adolescent and the ethnic community on the one hand, and the adolescent and the native majority on the other. The reality is even more complex and may even require three-way interactions, because all three actors are connected in a triadic relationship. Unfortunately, our data did not possess the statistical power to test such three-way interactions (or other possible threeway interactions, such as in-group orientation $\times$ out-group orientation $\times$ context). Future research with larger data sets may address these possibilities in even greater detail.

Furthermore, we only focused on two groups, native Germans and ethnic German Diaspora immigrants. Modern multicultural societies consist of many ethnic groups. Germany, for example, accommodates people from more than 130 nations (Meissner and Vertovec 2015) who differ in legal status, heritage culture, endowment with resources, group size, and group status. How these groups interact and affect each other in their adaptation is another complex area for investigation, which is further complicated by the fact that regional variations or variations in school type exist that we were not able to address. Future research may include more groups in highly diverse settings with a planned variation in school contexts, because adaptation is not just a two-group issue, and because adaptation may differ depending on criteria additional to the setting that we studied here.

The final limitation to mention refers to the order of effects. Our conceptual approach is based on Berry's (1997) theoretical model and assumed that acculturative hassles are the result of an interaction of the individual with the context, which, in turn, predicts the psychosocial adaptation of adolescent immigrants. Due to the crosssectional nature of our study, however, our data cannot support any causality assumption. The statistical associations found could, for example, also be the result of acculturative hassles forming a particular acculturation orientation in a particular setting. In reality, it seems most 
probable that acculturation orientations and acculturative hassles are linked through bidirectional dynamic processes so that both variables affect each other over time. Future research could address the direction of effects more thoroughly by using longitudinal assessments or intervention research.

\section{Conclusion}

This research has generated important insights into the utility of a person-by-context perspective on the acculturation experiences of immigrant youth. It showed that it is important to consider not only the perspective of the adolescent immigrants, but also that of native and co-ethnic peers. Cross-group behaviors had the greatest effect on acculturative hassles: the individual acculturation orientation towards natives was more decisive in the context of co-ethnic peers and the individual orientation towards the co-ethnic group was more decisive in the context of native peers. This finding shows the demands that immigrant adolescents face when navigating through the intergroup context of multicultural schools. As multiethnic schools are on the rise in modern, increasingly multicultural societies, our study certainly emphasizes the need to delve deeper into the complexity of adolescent immigrant experiences. A deeper understanding of immigrant experiences is particularly crucial against the background that these experiences are associated with the psychological functioning of adolescent immigrants (depressive symptoms, self-efficacy). It is, therefore, a societal aim to reduce acculturative hassles in order to provide people with the opportunity to thrive. On the most general level, our study is an indication that achieving this aim requires all parties to be involvedthe native group, the immigrant community, and the individual adolescent. It is not a task for which the immigrant adolescent is solely responsible. Only a joint effort will have positive consequences for both the adolescent immigrants and society.

Acknowledgments This project was funded through the German Israeli Project Cooperation (DIP-4.1) on behalf of the German Federal Ministry of Education and Research (BMBF). Principal investigators: Rainer K. Silbereisen, Gideon Fishman, Gustavo Mesch, and Zvi Eisikovits.

Author contribution P.F.T. and P.J. conceived of the study. P.F.T. participated in the design and data collection and drafted parts of the manuscript, particularly with regard to acculturation and immigration perspective. P.J. conducted most analyses for the study and drafted parts of the manuscript, particularly with regard to the intergroup perspective. Both authors participated in the interpretation of the data, read, edited, and approved the final manuscript.

Conflict of interest The authors report no conflict of interests.

\section{References}

Achenbach, T. (1991) Manual for the child behavior checklist/4-18 and 1991 profile. Burlington: University of Vermont, Department of Psychiatry.

Agnew, R. (2003). An integrated theory of the adolescent peak in offending. Youth and Society, 34(3), 263-299. doi:10.1177/ $0044118 \times 02250094$.

Berry, J. W. (1997). Immigration, acculturation, and adaptation. Applied Psychology: An International Review, 46(1), 5-34. doi:10.1080/026999497378467.

Berry, J. W. (2006). Mutual attitudes among immigrants and ethnocultural groups in Canada. International Journal of Intercultural Relations, 30(6), 719-734. doi:10.1016/j.ijintrel.2006. 06.004.

Bochner, S., McLeod, B. M., \& Lin, A. (1977). Friendship patterns of overseas students: A functional model. International Journal of Psychology, 12, 277-294.

Bourhis, R. Y., Moïse, L. C., Perreault, S., \& Senécal, S. (1997). Towards an interactive acculturation model: A social psychological approach. International Journal of Psychology, 32(6), 369-386. doi:10.1080/002075997400629.

Bradley, R. H., \& Corwyn, R. F. (2002). Socioeconomic status and child development. Annual Review of Psychology, 53(1), 371-399. doi:10.1146/annurev.psych.53.100901.135233.

Brenick, A., \& Killen, M. (2014). Moral judgments about JewishArab intergroup exclusion: The role of cultural identity and contact. Developmental Psychology, 50(1), 86-99. doi:10.1037/ a0034702.

Brenick, A., Titzmann, P. F., Michel, A., \& Silbereisen, R. K. (2012). Perceptions of discrimination by young diaspora migrants: Individual- and school-level associations among adolescent ethnic German immigrants. European Psychologist, 17(2), 105-119. doi:10.1027/1016-9040/a000118.

Dietz, B. (2003). Post-Soviet youth in Germany: Group formation, values and attitudes of a new immigrant generation. In T. Horowitz, B. Kotik-Friedgut, \& S. Hoffman (Eds.), From pacesetters to dropouts. Post-Soviet youth in comparative perspective (pp. 253-271). Lanham, MD: University Press of America.

Förster, P., Friedrich, W., Müller, H., \& Schubarth, W. (1993). Jugend Ost: Zwischen Hoffnung und Gewalt [Youth in the East: Between hope and violence]. Opladen: Leske \& Budrich.

Frankenberg, E., Kupper, K., Wagner, R., \& Bongard, S. (2013). Immigrant youth in Germany. European Psychologist, 18(3), 158-168. doi:10.1027/1016-9040/a000154.

Havighurst, R. J. (1972). Developmental tasks and education. New York: David McKay Company Inc.

Hox, J. (2002). Multilevel analysis: Techniques and applications. Mahwah, NJ: Lawrence Erlbaum.

Hwang, W.-C. (2006). Acculturative family distancing: Theory, research, and clinical practice. Psychotherapy: Theory, research, practice. Training, 43(4), 397-409. doi:10.1037/0033-3204.43.4. 397.

Jasinskaja-Lahti, I., Liebkind, K., Horenczyk, G., \& Schmitz, P. (2003). The interactive nature of acculturation: Perceived discrimination, acculturation attitudes and stress among young ethnic repatriates in Finland, Israel and Germany. International Journal of Intercultural Relations, 27(1), 79-97. doi:10.1016/ S0147-1767(02)00061-5.

Jugert, P., Eckstein, K., Noack, P., Kuhn, A., \& Benbow, A. (2013). Offline and online civic engagement among adolescents and young adults from three ethnic groups. Journal of Youth and Adolescence, 42(1), 123-135. doi:10.1007/s10964-012-9805-4.

Kunst, J. R., \& Sam, D. L. (2013). Relationship between perceived acculturation expectations and Muslim minority youth's 
acculturation and adaptation. International Journal of Intercultural Relations, 37(4), 477-490. doi:10.1016/j.ijintrel.2013.04. 007.

Lay, C. H., \& Safdar, S. F. (2003). Daily hassles and distress among college students in relation to immigrant and minority status. Current Psychology, 22(1), 3-22. doi:10.1007/s12144-0031009-3.

Meissner, F., \& Vertovec, S. (2015). Comparing super-diversity. Ethnic and Racial Studies, 38(4), 541-555. doi:10.1080/ 01419870.2015 .980295$.

Miranda, A. O., \& Matheny, K. B. (2000). Socio-psychological predictors of acculturative stress among Latino adults. Journal of Mental Health Counseling, 22(4), 306-317.

Motti-Stefanidi, F., Berry, J., Chryssochoou, X., Sam, D. L., \& Phinney, J. (2012). Positive immigrant youth adaptation in context: Developmental, acculturation, and social-psychological perspectives. In A. S. Masten, K. Liebkind, \& D. J. Hernandez (Eds.), Realizing the potential of immigrant youth. (pp. 117-158, The Jacobs Foundation series on adolescence). New York, NY US: Cambridge University Press.

Motti-Stefanidi, F., Pavlopoulos, V., Obradović, J., \& Masten, A. S. (2008). Acculturation and adaptation of immigrant adolescents in Greek urban schools. International Journal of Psychology, 43(1), 45-58. doi:10.1080/00207590701804412.

O'Brien, R. M. (1990). Estimating the reliability of aggregate-level variables based on individual-level characteristics. Sociological Methods and Research, 18(4), 473-504. doi:10.1177/ 0049124190018004004.

Oppedal, B. (2006). Development and acculturation. In D. L. Sam \& J. W. Berry (Eds.), The Cambridge handbook of acculturation psychology (pp. 97-112). New York, NY: Cambridge University Press.

Petersen, A. C., Sarigiani, P. A., \& Kennedy, R. E. (1991). Adolescent depression: Why more girls? Journal of Youth and Adolescence, 20(2), 247-271. doi:10.1007/BF01537611.

Piontkowski, U., Rohmann, A., \& Florack, A. (2002). Concordance of acculturation attitudes and perceived threat. Group Processes and Intergroup Relations, 5(3), 221-232. doi:10.1177/ 1368430202005003003

Ramos, M. R., Cassidy, C., Reicher, S., \& Haslam, S. A. (2015). Well-being in cross-cultural transitions: Discrepancies between acculturation preferences and actual intergroup and intragroup contact. Journal of Applied Social Psychology, 45(1), 23-34. doi:10.1111/jasp.12272.

Raudenbush, S. W., Bryk, A., \& Congdon, R. (2005). HLM 6: SSI [Computer Software]. Lincolnwood, IL: Scientific Software International.

Rudmin, F. W. (2003). Critical history of the acculturation psychology of assimilation, separation, integration, and marginalization. Review of General Psychology, 7(1), 3-37. doi:10.1037/10892680.7.1.3.

Ryder, A. G., Alden, L. E., \& Paulhus, D. L. (2000). Is acculturation unidimensional or bidimensional? A head-to-head comparison in the prediction of personality, self-identity, and adjustment. Journal of Personality and Social Psychology, 79(1), 49-65. doi:10.1037/0022-3514.79.1.49.

Safdar, S., \& Lay, C. H. (2003). The relations of immigrant-specific and immigrant-nonspecific daily hassles to distress controlling for psychological adjustment and cultural competence. Journal of Applied Social Psychology, 33(2), 299-320. doi:10.1111/j. 1559-1816.2003.tb01898.x.

Schiefer, D., Möllering, A., \& Daniel, E. (2012). Cultural value fit of immigrant and minority adolescents: The role of acculturation orientations. International Journal of Intercultural Relations, 36(4), 486-497. doi:10.1016/j.ijintrel.2012.02.001.
Schwarzer, R., \& Jerusalem, M. (1995). Generalized self-efficacy scale. In Weinman, J., Wright, S. \& Johnston, M. (Eds.), Measures in health psychology: A user's portfolio. Causal and control beliefs (pp. 35-37). Windsor, England: NFER-NELSON.

Statistisches Bundesamt (2010). Bevölkerung und Erwerbstätigkeit. Bevölkerung mit Migrationshintergrund [Population and earning capacity: Population with migrant background]. Wiesbaden: Statistisches Bundesamt.

Stoessel, K., Titzmann, P. F., \& Silbereisen, R. K. (2014). Being 'them' and 'us' at the same time? Subgroups of cultural identification change among adolescent diaspora immigrants. Journal of Cross-Cultural Psychology, 45(7), 1089-1109. doi:10.1177/0022022114534770.

Thijs, J., \& Verkuyten, M. (2014). School ethnic diversity and students' interethnic relations. British Journal of Educational Psychology, 84(1), 1-21. doi:10.1111/bjep.12032.

Thijs, J., Verkuyten, M., \& Grundel, M. (2014). Ethnic classroom composition and peer victimization: The moderating role of classroom attitudes. Journal of Social Issues, 70(1), 134-150. doi:10.1111/josi.12051.

Titzmann, P. F. (2014). Immigrant adolescents' adaptation to a new context: Ethnic friendship homophily and its predictors. Child Development Perspectives, 8(2), 107-112. doi:10.1111/cdep.12072.

Titzmann, P. F., Brenick, A., \& Silbereisen, R. K. (2015). Friendships fighting prejudice: A longitudinal perspective on adolescents' cross-group friendships with immigrants. Journal of Youth and Adolescence, 44(6), 1318-1331. doi:10.1007/s10964-015-0256-6.

Titzmann, P. F., \& Silbereisen, R. K. (2012). Acculturation or development? Autonomy expectations among ethnic German immigrant adolescents and their native German age-mates. Child Development, 83(5), 1640-1654. doi:10.1111/j.1467-8624.2012.01799.x.

Titzmann, P. F., Silbereisen, R. K., \& Mesch, G. (2014). Minor delinquency and immigration: A longitudinal study among male adolescents. Developmental Psychology, 50(1), 271-282. doi:10. 1037/a0032666.

Titzmann, P. F., Silbereisen, R. K., Mesch, G. S., \& SchmittRodermund, E. (2011). Migration-specific hassles among adolescent immigrants from the former Soviet Union in Germany and Israel. Journal of Cross-Cultural Psychology, 42(5), 777-794. doi:10.1177/0022022110362756.

Tsuda, T. (2009). Diasporic homecomings: Ethnic return migration in comparative perspective. Stanford, Calif.: Stanford University Press.

Unger, J., Ritt-Olson, A., Wagner, K., Soto, D., \& BaezcondeGarbanati, L. (2007). A comparison of acculturation measures among hispanic/latino adolescents. Journal of Youth and Adolescence, 36(4), 555-565. doi:10.1007/s10964-007-9184-4.

Vinokurov, A., Trickett, E. J., \& Birman, D. (2002). Acculturative hassles and immigrant adolescents: A life-domain assessment for Soviet Jewish refugees. The Journal of Social Psychology, 142(4), 425-445. doi:10.1080/00224540209603910.

Williams, C. L., \& Berry, J. W. (1991). Primary prevention of acculturative stress among refugees: Application of psychological theory and practice. American Psychologist, 46(6), 632-641. doi:10.1037/0003-066X.46.6.632.

Zagefka, H., \& Brown, R. (2002). The relationship between acculturation strategies, relative fit and intergroup relations: Immigrant-majority relations in Germany. European Journal of Social Psychology, 32(2), 171-188. doi:10.1002/ejsp.73.

Peter F. Titzmann is currently Associate Professor at the Jacobs Center for Productive Youth Development, University of Zurich, Switzerland. His general research interest is in the interplay between normative development and migration-related adaptation among 
adolescents with immigrant background. He investigated this interplay in various developmental outcomes, such as experiences of stress, delinquent behaviour, friendships, and autonomy development.

Philipp Jugert is a research associate at the University of Leipzig. He received his Ph.D. in Psychology from the University of Jena. His major research interests include social-developmental psychology, group processes and intergroup relations, authoritarianism, and civic engagement. 